\title{
Impact of COVID-19 on Medical Education in Bangladesh
}

Rajat Sanker Roy Biswas ${ }^{1 *}$

Md Jalal Uddin ${ }^{2}$

'Department of Medicine

Chattogram Maa-O-Shishu Hospital Medical College Chattogram, Bangladesh.

${ }^{2}$ Department of Community Medicine Chattogram Maa-O-Shishu Hospital Medical College Chattogram, Bangladesh.
${ }^{*}$ Correspondence to:

\section{Dr. Rajat Sanker Roy Biswas}

Assistant Professor

Department of Medicine

Chattogram Maa-O-Shishu Hospital Medical College Chattogram, Bangladesh.

Mobile : +8801819808433

Email: rajatbiswas76@yahoo.com

Date of Submission : 15.06 .2020

Date of Acceptance ： 07.07.2020
Corona pandemic is a worldwide disaster including Bangladesh. All types of schools, colleges and universities have been closed to prevent the transmission of the virus. As gathering is a risky behavior and the maintenance of social-distance is crucial to prevent the spread of the disease these are accepted by the students and teachers. As the number of patients of Covid-19 has been increasing in an exponential fashion this types of intervention were necessary to implement stay home approach at all levels. But all types of educational institutions general to professional like medical and engineering are facing different types of challenges due to long term closure $^{1}$. So these have an impact on the educational behavior of the students. So it is the time to think for them to plan and to implement some strategy to overcome the present calamity on their education.

Covid-19 disease has touched lifestyle to economy, playground to churchyard, primary education to medical education ${ }^{1}$. Academic activities of all medical colleges and universities are stopped, lectures and ward classes are in sleep, none knows when their examinations will resume. Students are loosing their academic continuities. Medical students need to learn with the principles of Knowledge, Skill and Attitude (KSA). They need to read the books to attain knowledge then they need to practical activities like dead body or model study in early years and patient study in later years. With that gained knowledge and skill they will reform their attitude as a future doctor. For that a proper and full functioning college and hospital is a must. But this present pandemic all the systems have been broken, students are in locked down condition. Their problems are deepening day by day.

Some colleges like Chattogram Maa-O-Shishu Hospital Medical College discussed the issue with all faculties and they planned to take online class with ZOOM which started from the early days of pandemic. It was an excellent decision and all preclinical, para clinical and clinical teachers started to take classes. Here again coordination with the teachers and respective class students is important. Class prosector should have a managing responsibility for a successful class. Another problem is quality of slides and sounds. If the slides are ill prepared then most of the students would miss the contents. Sound should be audible as sometimes it is the only media to reach the students. A one hour Zoom aided class needs at least $200 \mathrm{MB}$ internet. It is sometimes costly for the students as they need to have multiple classes in a week.

Again to mention only audio visual online based classes can provide theoretical concept. Providing total practical concept is maximum times impossible by the Zoom aided activities ${ }^{2}$. So we should not be satisfied that we have done a lot after taking an online class. We should keep in mind that only gaining knowledge of basic points is not enough for a complete medical concept. It needs integrations with the development of skills and then finally modified by gaining a proper attitude. So we would have a big task pending for those students in future. 
Taking class basis examinations which is generally known as items are all pending till date. So, after end of the pandemic when all will be opened subject teachers would have a big task to do. Card finals and block examinations are also should be made up to date. Next will come the matter of presence in the class for the eligibility of the professional examinations. Course coordinators should set up a general rule to solve this issue. Regular professional examinations are stopped. So universities and college faculties should make an acceptable plan to take the examinations within a short term notice. They may notify the students early so that in a short term notice examinations can be implemented. Otherwise session jam of examinations will produce new problems. So they might think of merging students of two years to overcome session jam.

Next issue is the internship. It is the last and final protocol to make a graduate doctor. But due to panic and fears, interns of different hospitals have omitted themselves from the duties or not joined to start their internship. They mentioned the cause behind it like as there are no regular academic activities like morning meeting, ward round with academic smell and seminar, they will be produced as an incomplete doctor for which they are not joining. It is true that they would lack the different regular academic activities of normal time but going away from the ward activities might produce more problem and they will loose their valuable time to become a complete BMDC certified future doctor.

Finally, post graduate medical education also is in a problem. Training time is going on without gaining necessary clinical knowledge. Trainees are involved in dealing Covid patients and they are missing their preparation time to prepare themselves for the examinations. Only declaring examination schedule and time will not solve the issue. Post graduate training centers and authorities should think of that and they should plan properly keeping in mind about the trainees involved in Covid 19 treatment. They should rethink about how they consider or weigh this covid period as training period for the trainees.

Medical education should be upto the mark to make a complete and safe doctor for the mankind. Covid -19 pandemic has made a complex situation for the students as well as for the teaching colleges and universities. Early thinking, proper planning and in time implementation will solve all and then only a new doctor can say loudly, "Yaa! We are ready to serve the humanity"!

\section{REFERENCES}

1. Pattanshetti VM, Pattanshetti SV. The impact of COVID-19 on medical education in India. J Sci Soc. 2020;47:1-2.

2. Goh PS, Sandars J. A Vision of the use of Technology in Medical Education after the COVID-19 Pandemic. MedEdPublish. 2020;9. 